\title{
Low sputum smear positive tuberculosis among pulmonary tuberculosis suspects in a tertiary hospital in Mwanza, Tanzania
}

\author{
JEREMIAH SENI ${ }^{*}$, BENSON R. KIDENYA ${ }^{1}$, EMMANUEL OBASSY $^{1}$, MARIAM MIRAMBO $^{1}$, \\ VENANCE BURUSHI ${ }^{1}$, HUMPHREY D. MAZIGO ${ }^{1}$, ANTONY KAPESA ${ }^{1}$, MTEBE MAJIGO ${ }^{2}$ and \\ STEPHEN E. MSHANA ${ }^{1}$ \\ ${ }^{1}$ Catholic University of Health and Allied Sciences-Bugando P.O. Box 1464 Mwanza, Tanzania \\ ${ }^{2}$ Institute of Human Virology, University of Maryland School of Medicine, USA
}

\begin{abstract}
Early diagnosis of tuberculosis (TB) and prompt initiation of treatment are essential for an effective tuberculosis control programme. In many resource limited settings microscopic diagnosis is still the pivotal tool in the diagnosis of pulmonary TB. This study aimed at evaluating laboratory microscopic diagnosis of tuberculosis in a tertiary hospital in Mwanza, Tanzania. This retrospective hospital based study reviewed consecutively from TB registry and patients' files a total of 5,922 TB suspects who submitted their sputum for examination between January 2007 and May 2010 at Bugando Medical Centre (BMC). Among TB suspects (mean age $=36.1 \pm 13.6$ years) female accounted for $54.1 \%$ of the patients. The prevalence of HIV among TB patients was $59.4 \%$. The sputum smear positivity rate among the TB suspects was $6.1 \%$; the rate was higher in HIV positive than in HIV negative patients $(9.9 \%$ versus $3.2 \%, P$-value $<0.001)$. The overall positivity rate for the first smear was $94.2 \%$ with an incremental percentage yield of $5.2 \%$ and $0.6 \%$ for the second and third smears, respectively. The study found that $28.6 \%$ of patients who were positive in the first smear did not return for the second smear. The risk factors among smear positive TB patients were co-illness $(32.5 \%)$, previous history of TB $(7.5 \%)$ and history of positive TB contact $(4.7 \%)$. These findings also show that as CD4+ T Cells count increases, the quantity AFB in sputum smear also increase although not statistically significant. The sputum smear positivity rate at Bugando Medical Centre is low and more than a quarter of initial TB suspects who were positive in the first smear were lost to follow up posing a threat of continuous transmission of tuberculosis to the community. The finding of more sputum smear positivity rate among HIV positive than HIV negative patients at BMC requires a prospective study to ascertain whether it is a reality or a coincidence.
\end{abstract}

Key words: Sputum smears, tuberculosis, HIV, Tanzania

\section{Introduction}

Tuberculosis (TB) is an important cause of morbidity and mortality in low-income countries (Frieden, 2003). Globally, it is estimated that there are 8.8 million new cases of tuberculosis, of which 3.9 million are sputum smear-positive and, thus, highly infectious (Corbett et al., 2003, WHO, 2005b). In the African region the tuberculosis case rate continues to increase, both because of the epidemic of HIV infection and the poor or absent primary care services in parts of the region (WHO, 1997; Dye et al., 1999; Corbett et al., 2003; Frieden, 2003). Early diagnosis of the disease and prompt initiation of treatment are essential for an effective tuberculosis control programme, therefore rapid

\footnotetext{
* Correspondence: Jeremiah Seni; Email: senijij0@gmail.com
} 
and accurate identification of infected individuals is mandatory (WHO, 2005a; Mandell et al., 2005). Delay in the diagnosis may worsen the disease, increase the risk of death and enhance tuberculosis transmission in the community (Rouillon et al., 1976; Toman, 1979). To confirm the diagnosis of pulmonary TB, Mycobacterium tuberculosis from the sputum should be cultured. However, because mycobacterial culture requires expensive equipment and the long turn-around time (WHO, 2005a), the simpler and easier acidfast bacilli (AFB) Ziehl-Neelsen (ZN) stain is still used widely as the pivotal tool in the diagnosis of TB and evaluation of treatment responses (WHO, 1998, 2001; Enarson et al., 2000). The standard recommendation, to obtain three sputum smears; spot-morningspot has been implemented in Tanzania (Ipuge et al., 1996; Enarson et al., 2000; MoHSW, 2006). However, currently there is a concern on the value of the third specimen especially in the developing world. Some studies have revealed that the increase in smear positivity obtained with the third specimen is low and probably not cost effective (Harries et al., 1996; Walker et al., 2000; Wu \& Wang, 2000; Crampin et al., 2001; Van Deun et al., 2002).

Patients with HIV/AIDS have been shown to pose challenge on microscopic diagnosis of pulmonary TB (PTB) and most literatures have shown that HIV/AIDS is associated with low sputum smear positivity (Klein et al., 1989; Elliot et al., 1993; Karstaedt et al., 1998; Matee et al., 2008), nevertheless other literatures have shown no significant difference between HIV positive and HIV negative patients (Long et al., 1991; Githui et al., 1992; Finch \& Beaty, 1997). To increase yield of sputum smear positivity, a number of methods, including concentration of sputum, use of fluorescent microscopy, internal and external quality control have been employed (Rieder et al., 1998; WHO, 2001, 2005; Steingart et al., 2005).

The International Union Against Tuberculosis and Lung Diseases (IUATLD) recommends screening an average of 10 suspects to identify one smear-positive case (IUATLD, 1978). In a study in Tanzania, it was shown that the average proportion of TB cases among TB suspects is 18.9\% (range 14.3-23.8\%) (Ipuge et al., 1996). However the detection rate in our setting remains unknown. Therefore, this study was carried out to evaluate laboratory microscopic diagnosis of tuberculosis in an area of HIV high endemicity to provide baseline data for Bugando Medical Centre where culture is not routinely done.

\section{Materials and Methods}

\section{Study design and patients}

This retrospective hospital-based study was conducted at Bugando Medical Centre (BMC) in Mwanza in northern Tanzania. BMC is the referral, consultant and teaching hospital serving approximately 13 million people from six regions around Lake Victoria and Western Zones of Tanzania.

All patients with clinically suspected PTB (MoHSW, 2006) and who submitted their sputum for examination at BMC TB Laboratory between January 2007 to May 2010 were included in the study. The sputum sample results of TB suspects were obtained 
from TB laboratory registry. The Bugando Medical Centre TB laboratory does routinely sputum smear microscopy by $\mathrm{ZN}$ stain method according to WHO recommended protocol. Briefly the primary stain was done using $0.3 \%$ of carbolfuchsin for five minutes; then decolourization with $3 \%$ acid alcohol or $25 \%$ sulphuric acid for one to two minutes and finally, counterstain with $0.3 \%$ methylene blue for one minute (WHO, 1998; Enarson et al., 2000). Patient clinical history, HIV serostatus, CD4+ T cell counts and other demographic characteristics were obtained from TB clinic registry and in patient' files. TB suspects whose data were missing in the TB registry and/or- files were excluded in the analysis.

\section{Data analysis}

Variables from the registry and patient' files were double entered into the computer, verified and cleaned using Epi info software version 3.1 (CDC, Atlanta) and analysis was done using STATA software version 11 (College Station, Texas). Continuous variables were described as mean ( \pm standard deviation). Categorical variables were described as proportion and were analyzed to compare the significance of difference in distribution by using Chi-square test or Fischer's exact test where appropriate. The difference in distribution was considered significant if $p$-value was less than 0.05 .

\section{Ethical clearance}

The study sought clearance from the Weill Bugando University College of Health Sciences/Bugando Medical Centre research and ethics committee. Permission to conduct the study was obtained from the Director General of BMC, heads of respective departments and TB Coordinator. All patients' information obtained from TB registry and patient's files were kept anonymously.

\section{Results}

In a period from January 2007 to May 2010 a total 5,922 TB suspects were retrospectively recruited in this study. Among these 3,204 (54.1\%) were females and 2,718 (45.9\%) were males. The female: male ratio among the TB suspects was 1.17: 1 . The mean age was 36.1 \pm 13.6 years. Of the studied population 2,171 (36.7\%) were HIV positive and 2,197 (37.1\%) were HIV negative. The HIV serostatus of 1,554 (26.2\%) was unknown. Among the population studied smear positive was detected in $360(6.1 \%)$ patients, of these 214 (59.4\%) were HIV positive, 71 (19.7\%) were HIV negative and 75 (20.8\%) had their HIV serostatus unknown. TB smear positivity rates were significantly higher in HIV positive than in HIV negative $(9.9 \%$ vs $3.2 \%, P$-value $<0.001)$ (Figure 1$)$. 


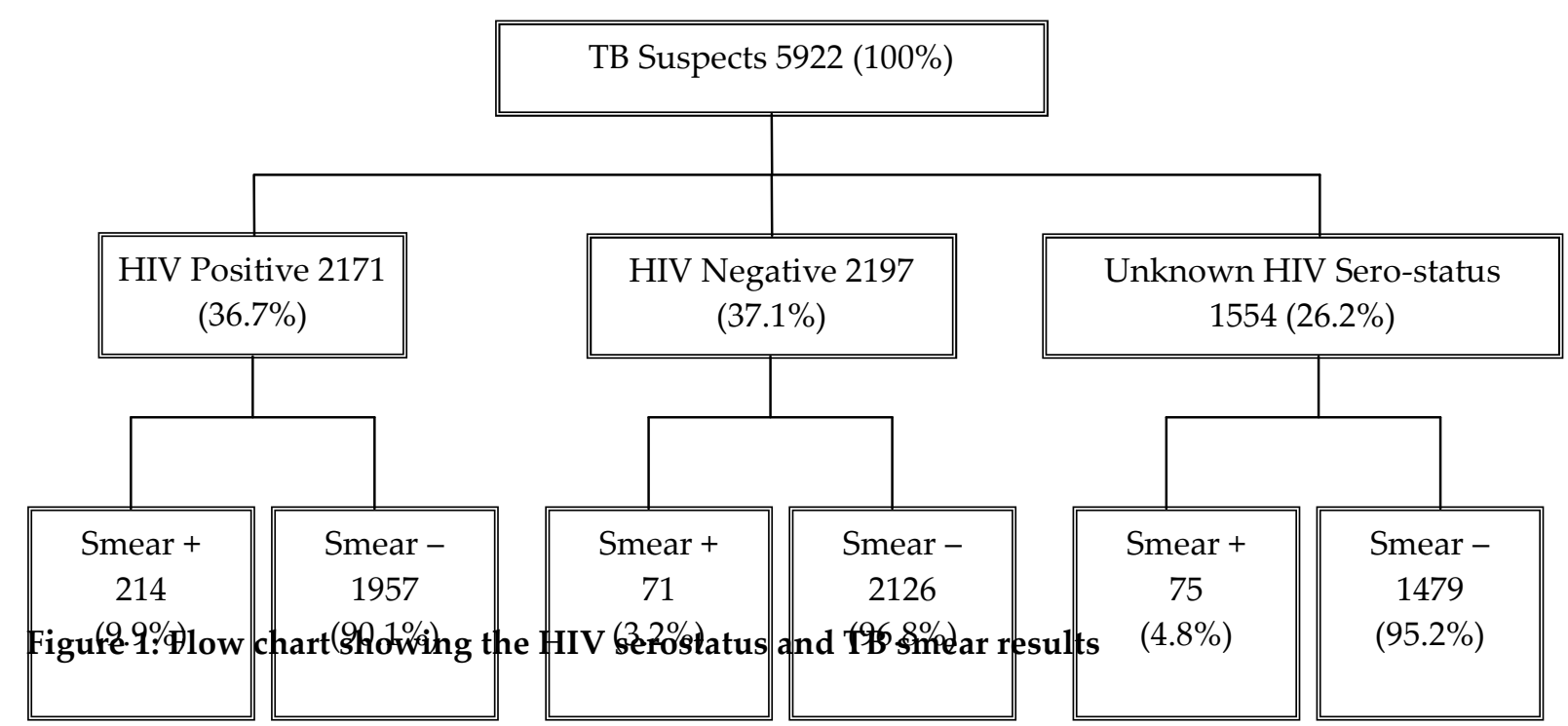

The positivity rate for the first smear was $94.2 \%$ with an incremental percentage yield of $5.2 \%$ and $0.6 \%$ for the second and third smears respectively (Table 1 ).

Table 1: Incremental yield in the smear positivity among TB positive patients

\begin{tabular}{lll}
\hline Smear Number & Number of positive smear & Incremental percentage yield \\
\hline First smear & 339 & 94.2 \\
Second smear & 19 & 5.2 \\
Third smear & 2 & 0.6 \\
\hline Total & 360 & 100 \\
\hline
\end{tabular}

The study found that $28.6 \%$ (97/339) of patients who were positive in the first smear did not return for the second smear. The clinical characteristics presented by the smear positive TB suspects were persistent productive cough $(93.3 \%)$, fever $(64.2 \%)$, recent weight loss $(47.5 \%)$, night sweats $(43.9 \%)$ and chest pain $(41.7 \%)$. Persistent productive cough, chest pain and haemoptysis were observed more frequently among HIV positive than in HIV negative patients; $P$-values $0.027,<0.0001$ and 0.008 respectively (Table 2 ).

Table 2: Comparison of Clinical characteristics among HIV positive and HIV negative smear positive patients

\begin{tabular}{llll}
\hline Clinical characteristics (N) & HIV Positive n (\%) & HIV Negative n (\%) & p- value \\
\hline Persistent cough (264) & $194(73.5)$ & $70(26.5)$ & 0.027 \\
Fever (185) & $135(73.0)$ & $50(27.0)$ & 0.262 \\
Recent weight loss (134) & $97(72.4)$ & $37(27.6)$ & 0.321 \\
Night sweats (130) & $98(75.4)$ & $32(24.6)$ & 0.915 \\
Haemoptysis (41) & $24(58.5)$ & $17(41.5)$ & 0.008 \\
Chest pain (111) & $69(62.2)$ & $42(37.8)$ & 0.000 \\
Malaise (96) & $68(70.8)$ & $28(29.2)$ & 0.237 \\
\hline
\end{tabular}

The risk factors identified among smear positive TB patients were co-illness (32.5\%), previous history of $\mathrm{TB}(7.5 \%)$ and history of positive TB contact $(4.7 \%)$. Among the 
sputum smear positive HIV patients, 147 (68.7\%) had their CD4+ T cells count measured and recorded, with the median CD4+ of 161.5 cells $/ \mu \mathrm{L}$ (range $1-1410$ cells $/ \mu \mathrm{L}$ ). These findings show that as CD4+ T Cells count increases, the quantity AFB in sputum smear also increase although not statistically significant.

Table 3: Quantification of AFB in Sputum Smear Positive Results with CD4+ T Cell Counts

\begin{tabular}{lllll}
\hline \multicolumn{5}{c}{ Quantity of AFB in Sputum Smears } \\
& & $\leq$ AFB 1+ & AFB 2+ and 3+ & Total \\
\hline CD4+ Counts & $\leq 200$ & $28(34.2 \%)$ & $54(65.8 \%)$ & $82(100.0 \%)$ \\
CD4+ Counts & $>200$ & $18(27.7 \%)$ & $47(72.3 \%)$ & $65(100.0 \%)$ \\
\hline
\end{tabular}

Chi square 0.702 , p- value 0.402 .

\section{Discussion}

In this study, the mean age was similar to findings from a previous study by Yusuphy et al. (2008). The prevalence of HIV among TB patients of 59.4\% in our study correlates to the previous findings elsewhere in Tanzania and other part of Africa (WHO, 1997; MoHSW, 2006, 2008). However, this rate is lower compared to studies from developed countries (Dye et al., 1999; Wang et al., 2009). Among the population studied smear positivity rate was $6.1 \%$, a value lower than the recommended rate of $10 \%$ (IUATLD, 1978) and values reported by another study in Tanzania (Ipuge et al., 1996) and in other countries (Yassin \& Cuevas, 2003; Saleem et al., 2007). The value of $10 \%$ from IUATLD was based on ZN TB Microscopy, so the use of both ZN stain for AFB and fluorescence microscopy as it is in our setting is expected to yield higher detection rate. At Bugando Medical Centre there is no external quality control system, which could explain the low detection rate. Also high index of suspicion of clinician with less stringy criteria at BMC is likely to contribute to the low detection rate.

This study found that HIV infected people were significantly more prone to PTB than HIV negative individuals. Other studies have also reported higher sputum smear positivity rate among HIV positive than HIV negative patients (Garcia et al., 2009; Wanga et al., 2009).

The percentage yield from the first smear was $94.2 \%$ with an incremental percentage yield of $5.2 \%$ and $0.6 \%$ for the second and third smears, respectively. This showed that the role of the third smears is not cost effective as the yield was very low as previously reported (Harries et al., 1996; Wu \& Wang, 2000; Crampin et al., 2001; Van Deun et al., 2002; Yassin \& Cuevas, 2003). However, a few studies have reported higher values in the second and third smears ((Ipuge et al., 1996; Saleem et al., 2007). The proposed recommendation by WHO to consider reducing the number of smears from three to two (WHO, 2001) is emphasized from our findings.

In this study, two-thirds of the sputum smear positive HIV patients had their CD4+ $\mathrm{T}$ cells count measured. There was an insignificant increase in CD4+ count as the quantity AFB in sputum smear increased. Other studies elsewhere have shown a significant association between an increase in CD4+ and increase in the quantify of AFB in sputum smear (Watson \& Gill, 1990; Attili et al.,2005). 
The study found that just about one-third of patients who were positive in the first smear did not return for the second smear, thus posing a potential risk of transmitting tuberculosis to the community. Already a study by Bruchfeld et al. (2002) have shown that persistent productive cough, chest pain and haemoptysis are more frequent among TB-HIV positive than among TB- HIV negative patients.

Conclusively, the sputum smear positivity rate at Bugando Medical Centre is low and more than a quarter of the TB suspects who are positive in the first smear are lost to follow up posing a threat of continuous transmission of tuberculosis to the community. These findings call for laboratory, clinical and community-based interventions to combat the situation. The proposed recommendation by WHO to consider reducing the number of smears from three to two is emphasized in our findings. The finding of more sputum smear positivity rate among HIV positive than HIV negative at BMC requires a prospective study to ascertain whether it is a reality or a coincidence.

\section{Acknowledgements}

The authors would like to express their sincere gratitude to Profs. W.D. Johnson and D. Fitzgerald of Weill Cornell Medical College, USA for provision of grant through Center for Global Health to fund this work. Special thanks to Bugando Medical Centre TB Laboratory and Medical Record personnel for their assistance. Dr. Charles Majinge, the Director General of BMC is thanked for provision of a conducive environment for the study.

\section{References}

Attili, V.S.S., Singh, V.P., Rai, M., Varma, D.V. \& Sundar, S. (2005) Evaluation of the status of tuberculosis as part of the clinical case definition of AIDS in India. Postgraduate Medical Journal 81, 404-408.

Bruchfeld, J., Aderaye, G., Palme, I.B., Bjorvatn, B., Britton, S., Feleke, Y., Källenius, G. \& Lindquist, L. (2002) Evaluation of outpatients with suspected pulmonary tuberculosis in a high HIV prevalence setting in Ethiopia: Clinical, diagnostic and epidemiological characteristics. Scandinavian Journal of Infectious Diseases 34, 331337.

Corbett, E.L., Watt, C.J., Walker, N., Maher, D.,Williams, B.G., Raviglione, M.C. \& Dye, C. (2003) The growing burden of tuberculosis: global trends and interactions with the HIV epidemic. Achieves of Internal Medicine 163, 1009-1021.

Crampin, A.C., Floyd, S., Mwaungulu, F., Black, G., Ndhlovu, R., Mwaiyeghele, E. \& Glynn, J.R. (2001) Comparison of two versus three smears in identifying culturepositive tuberculosis patients in a rural African setting with high HIV prevalence. International Journal of Tubercle and Lung Disease 5, 994-999.

Dye, C., Scheele, S., Dolin, P., Pathania, V. \& Raviglione, M.C. (1999) Consensus statement. Global burden of tuberculosis: estimated incidence, prevalence, and 
mortality by country. WHO Global surveillance and Monitoring project. JAMA $282,677-686$.

Enarson, D.A., Rieder, H.L., Arnadottir, T. \& Trébucq, A. (2000) In: Management of tuberculosis: a guide for low-income countries. Paris: International Union Against Tuberculosis and Lung Disease 1-89.

Finch, D. \& Beaty, C.D. (1997) The Utility of a single sputum specimen in the diagnosis of tuberculosis: comparison between HIV-infected and non-HIV-Infected Patients. Chest 111, 1174-1179.

Frieden, T.R., Sterling, T.R., Munsiff, S.S., Watt, C.J. \& Dye, C. (2003) Tuberculosis. Lancet 362, 887-899.

Garcia, S.B., Perin, C., Silveira, M.M., Vergani, G., Menna-Barreto., S.S. \& Dalcin, P.T.R. (2009) Bacteriological analysis of induced sputum for the diagnosis of pulmonary tuberculosis in the clinical practice of a general tertiary hospital. Jornal Brasileiro de Pneumologia 35,1092-1099.

Githui, W., Nunn, P., Juma, E., Karimi, F., Brindle, R., Kamunyi, R., Gathua, S., Gicheha, C., Morris, J. \& Omwega, M. (1992) Cohort study of HIV-positive and HIVnegative tuberculosis, Nairobi, Kenya: comparison of bacteriological results. Tubercle and Lung Disease 73, 203-209.

Harries, A.D., Kamenya, A., Subramanyam, V.R., Salaniponi, F.M. \& Nyangulu, D.S. (1996) Sputum smears for diagnosis of smear positive pulmonary tuberculosis. Lancet 347, 834-835.

Ipuge, Y.A.I., Rieder, H.L. \& Enarson, D.A. (1996) The yield of acid bacilli from serial smears in routine microscopy laboratories in rural Tanzania. Transactions of the Royal Society of Tropical Medicine and Hygiene 90, 258-261.

IUATLD (1978) Technical Guide for Sputum Examination for Tuberculosis by Direct Smear Microscopy, 3rd edn. International Union against Tuberculosis and Lung Diseases, Paris.

Karstaedt, A.S., Karstaedt, A.S., Jones, N., Khoosal, M. \& Crewe-Brown, H.H. (1998) The bacteriology of pulmonary tuberculosis in a population with high human immunodeficiency virus seroprevalence. International Journal of Tuberculosis and Lung Disease 2, 312-316.

Klein, N.C., Duncanson, F.P., Lenox, T.H., Pitta, A., Cohen, S.C. \& Wormser, G.P. (1989) Use of mycobacterial smears in the diagnosis of pulmonary tuberculosis in AIDS/ARC patients. Chest 95,1190-1192.

Long, R., Scalcini, M., Manfreda, J., Jean-Baptiste, M. \& Hershfield, E. (1991) The impact of HIV on the usefulness of sputum smears for the diagnosis of tuberculosis. American Journal of Public Health 81, 1326-1328.

Mandell, G.L., Bennett, J.E. \& Dolin, R. (2005) Principles and Practice of Infectious Diseases. Volume 2, $6^{\text {th }}$ Edition. Philadelphia: Elsevier Churchill Livingstone pp.2852-2886.

Matee, M., Mtei, L., Lounasvaara, T., Wieland-Alter, W., Waddell, R., Lyimo, J., Bakari, M., Pallangyo, K. \& von Reyn, F. (2008) Sputum microscopy for the diagnosis of HIV-associated pulmonary tuberculosis in Tanzania. BMC Public Health, 8:68. 
MoHSW (2006) Manual of the Tuberculosis and Leprosy Programme in Tanzania. $5^{\text {th }}$ Edition. Ministry of Health and Social Welfare, Dar es Salaam, Tanzania.

MoHSW (2008) National Guidelines for the Management of HIV and AIDS. $3^{\text {rd }}$ Edition. National AIDS Control Programme, Ministry of Health and Social Welfare, Dar es Salaam, Tanzania.

Rieder, H.L., Chonde, T.M., Myking, H., Urbanczik, R., Laszio, A. \& Kim, S.J. (1998) The Public Health Service National Tuberculosis Reference Laboratory and the National Laboratory Network International. Union against Tuberculosis and Lung Disease. ISBN 2-9504238-7-6.

Rouillon, A., Perdrizet, S. \& Parrot, R. (1976) Results of examination in Totterdum 19671969. Tubercle 57, 275-99.

Saleem, S., Shabbir, I., Iqbal, R. \& Khan, S.U. (2007) Value of three sputum smears microscopy in diagnosis of pulmonary tuberculosis. Pakistan Journal of Medical Research 46 (4).

Steingart, K.R., Ng, V., Henry. M., Hopewell, P.C., Ramsay, A., Cunningham, J., Urbanczik, R., Perkins, M.D., Aziz, M.A. \& Pai, M. (2005) Sputum processing methods to improve the sensitivity of smear microscopy for tuberculosis: a systematic review. Lancet Infectious Diseases 6: 664-674.

Toman, K. (1979) Tuberculosis Case Finding and Chemotherapy: Questions and Answers. World Health Organization, Geneva.

Van Deun, A., Salim, A.H., Cooreman, E., Hossain, M.A. \& Rema, A. (2002) Optimal tuberculosis case detection by direct sputum smear microscopy: how much better is more? International Journal of Tuberculosis and Lung Disease 6, 222-230.

Walker, D., McNerney, R., Mwembo, M.K., Foster, S., Tihon, V. \& Godfrey-Faussett, P. (2000) An incremental cost-effectiveness analysis of the first, second and third sputum examination in the diagnosis of pulmonary tuberculosis. International Journal of Tuberculosis and Lung Disease 4, 246-251.

Wang, G.J., Phypers, M. \& Ellis, E. (2009) Demographic, laboratory and clinical characteristics of HIV-positive tuberculosis cases in Canada. Journal of Infection and Public Health 2, 112-119.

Watson, J.M. \& Gill, O.N. (1990) HIV infection and tuberculosis. BMJ 300, $63-65$.

WHO (1997) World Health Organization Report on the Tuberculosis Epidemic, Geneva, Switzerland.

WHO (1998) World Health Organization Global Tuberculosis Programme. Laboratory services in tuberculosis control (WHO/TB/98.258 [Pt 2]). Geneva, Switzerland.

WHO (2001) Revision of a Case Definition of Sputum Smear Positive Pulmonary Tuberculosis. World Health Organization. Geneva, Switzerland

WHO (2005a) Expert Consultation on Improved the Diagnosis of Tuberculosis through Optimization of Sputum Microscopy. World Health Organization, Geneva, Switzerland.

WHO (2005b) Global tuberculosis control: surveillance, planning, financing. WHO report Geneva: World Health Organization; Geneva, Switzerland. 
Wu, Z.L. \& Wang, A.Q. (2000) Diagnostic yield of repeated smear microscopy examinations among patients suspected of pulmonary TB in Shandong province of China. International Journal of Tubercle and Lung Disease 4, 1086-1087.

Yassin, M.A. \& Cuevas, L.E. (2003) How many sputum smears are necessary for case finding in pulmonary tuberculosis? Tropical Medicine and International Health 8, 927-932.

Yusuphy, H., Zailani, S.B., Bakki, B., Garbati, M.A., Talle, M.A. \& Gadzama, G.B. (2008) Sputum smear positive tuberculosis among tuberculosis patients in a sub-urban hospital in Northeastern Nigeria. Nigerian Journal of Health and Biomedical Sciences 7, 72-75. 